\title{
E-cigarette in Malaysia: Reasons for Initiating of Electronic Cigarettes Among Hospital and Clinic Patients and Visitors
}

\author{
Abu Bakar Rahman 1, *, Mohamad Irwan Sai'din ${ }^{1}$, Nurashma Juatan ${ }^{1}$, Manimaran Krishnan ${ }^{1}$, \\ Zaikiah Mohd Zin ${ }^{1}$, Normawati Ahmad ${ }^{1}$, Mohd Yusoff Adon ${ }^{2}$, Siti Fathiah Mohamed ${ }^{1,3}$ \\ ${ }^{1}$ Institute for Health Behavioural Research, National Institutes of Health, Ministry of Health Malaysia, Shah Alam, Selangor, Malaysia \\ ${ }^{2}$ Institute for Medical Research, Ministry of Health Malaysia, Jalan Pahang, Kuala Lumpur, Malaysia \\ ${ }^{3}$ School of Health Sciences, Universiti Sains Malaysia, Kubang Kerian, Kelantan, Malaysia
}

Email address:

abubakar.rahman@moh.gov.my (A. B. Rahman), ctfathiah95@gmail.com (S. F. Mohamed)

${ }^{*}$ Corresponding author

\section{To cite this article:}

Abu Bakar Rahman, Mohamad Irwan Sai'din, Nurashma Juatan, Manimaran Krishnan, Zaikiah Mohd Zin, Normawati Ahmad, Mohd Yusoff Adon, Siti Fathiah Mohamed. E-Cigarette in Malaysia: Reasons for Initiating of Electronic Cigarettes Among Hospital and Clinic Patients and Visitors. Science Journal of Public Health. Vol. 9, No. 4, 2021, pp. 135-141. doi: 10.11648/j.sjph.20210904.13

Received: May 3, 2021; Accepted: May 24, 2021; Published: August 23, 2021

\begin{abstract}
The prevalence of electronic cigarettes (e-cigarettes) use has been increased and became a global concern. This cross-sectional study among adults in Malaysia determined the knowledge of e-cigarettes, the association between the factors of initiating e-cigarettes use and usage status, the predicting factors of initiating e-cigarettes use and the reasons for the users to stop using it. A total of 1254 respondents completed a self-constructed questionnaire on socio-demographics, knowledge, reasons for e-cigarettes initiation and cessation. Results showed that the majority of them (73.6\%) were aware of e-cigarette's existence, while $13.2 \%$ were e-cigarettes users. A significant association was found between curiosity to try and usage status in which former user has a higher curiosity to try $(55.7 \%)$ than the currents users $(\mathrm{p}=0.004)$. A variety of flavours has a significant association between usage status as current users $(58.8 \%)$ used e-cigarettes due to a variety of flavours than the former users $(38.6 \%)(\mathrm{p}=0.044)$. The findings showed that curiosity to try and e-cigarettes are safer are the predictors of initiating e-cigarettes. The respondents who believe that e-cigarettes are safer than tobacco cigarettes have 6.12 times chance to initiate using e-cigarette when considering other factors $(\mathrm{OR}=6.12, \mathrm{p}=0.018)$. Meanwhile, those who used e-cigarettes because of the curiosity to try had 0.32 times the chance to initiate e-cigarettes use $(\mathrm{OR}=0.32, \mathrm{p}=0.018)$. This study observed a low knowledge related to e-cigarettes and the significant predicting factor of initiating were a curiosity to try and e-cigarettes is safer. This study reported the main reason smokers quit using e-cigarettes was it did not give satisfaction compared to conventional cigarettes, while for non-smoker was due to worry about the danger of e-cigarettes. Therefore, appropriate information on e-cigarettes should be adequately disseminated to the general population to promote healthy behaviours and positive attitudes toward smoking.
\end{abstract}

Keywords: Electronic Cigarettes, E-cigarettes, Knowledge, Initiation, Adult

\section{Introduction}

The electronic cigarette, also called 'e-cigarette' or electronic nicotine delivery systems (ENDS) usage has increased worldwide throughout the years. An e-cigarette is a battery-operated device that produces a warm vapour by heating a cartridge. The cartridge can be filled with solutions known as e-liquid or e-juices containing nicotine, propylene glycol, or glycerol, and come with various flavours that potential to be additive [1]. The availability of e-cigarettes has been varied depending on their wide variation of nicotine level, liquid ingredients and flavouring that can bring to product manufacture's inconsistency [2]. In online searches, e-cigarettes were significantly the most searched for an alternative smoking device than others in the US, Australia, Canada, and United Kingdom [3].

Since the commercialization of e-cigarettes, it has become a debatable issue among many researchers and public health advocates in terms of its usefulness, potentially harmful effects and safety level. Several findings among smokers and 
former smokers suggested that e-cigarettes as a useful tool for reducing or eliminating smoking $[1,4]$ and represent a harm reduction strategy for smokers [5]. Other findings among the general population believe that e-cigarettes were more useful for reducing tobacco consumption than for quitting (50\% vs $30 \%$ of the population). They perceived that e-cigarettes helped to reduce tobacco consumption but not for reducing potentially harmful effects on users and passive smokers [6]. Besides, most smokers considered e-cigarettes as less likely to cause lung cancer, oral cancer or heart disease [7]; and some of the non-smokers believe that e-cigarettes were less harmful than conventional cigarettes [8]. Thus, much more evidence is needed to show its safety and the effectiveness of e-cigarettes for quitting cigarettes and other tobacco products.

According to the Center for Tobacco Control Research and Eduacation (2014), the majority of the tobacco control researchers and activists see e-cigarettes as a method of normalizing smoking in the public and working environment. This can contribute to the initiation of nicotine addiction among young people, including those who have never smoked [9]. The sleek design with various trendy flavours of e-cigarettes would attract non-smokers to experiment with it. They could subsequently develop nicotine addiction and might be switch to smoking ordinary cigarettes in the future. On the other hand, some of the e-cigarettes users are more likely to continue smoking and vaping, which is referred to as "dual-use" as they are adding another tobacco product [10].

Currently, public awareness and the prevalence of e-cigarettes use are growing even though the risks and benefits of e-cigarettes use are still unknown, particularly in the mid-term and long-term. Many studies have been conducted in different populations to assess their perception of the harmfulness and use of e-cigarettes around the world $[6,11$, 12]. However, there is still limited study in Malaysia studied on the issues related to e-cigarettes. Thus, this study aimed to identify the knowledge regarding e-cigarettes, the association between the factors of initiating e-cigarettes use and usage status, the predicting factors of initiating e-cigarettes use and the reasons for the users to stop using it.

\section{Materials and Methods}

\subsection{Study Design}

The study was carried out from June 2014 to July 2015. This is a cross-sectional study, using two-stage cluster sampling to select the respondents. First, the public hospitals and clinics were stratified into six zones: southern (Johor and Malacca), central (Selangor, Wilayah Persekutuan Kuala Lumpur, Wilayah Persekutuan Putrajaya and Negeri Sembilan), northern (Perak, Penang, Kedah and Perlis), east coast (Pahang, Kelantan and Terengganu), Sabah and Sarawak. Secondly, one or two public hospitals and health clinics from each zone were selected via a random sampling method. The sample size was determined based on the prevalence of e-cigarette use from Global Adult Tobacco Survey Malaysia 2011 (GATS-M 2011) which is $3.2 \%$ [13]. The precision/accuracy rate of $2.5 \%$ was used (precision/accuracy was defined as - how close the observed sample statistic comes to the true population parameter). A design effect of 3.137 was used to cater for the clustering effect from each locality. The sample size obtained was multiplied by two in view of two stages of stratification in the sampling, and an expected non-response rate of $10 \%$. Based on these parameters, a total of 1318 respondents were required for the study. The intercept approach was used in this study. Trained research team members approached every third person passing by the interview station to participate; if the respondent did not fulfill the inclusion criteria or refused to participate, the next person was selected. The self-administered questionnaire was distributed to the respondent after they consented in writing. The research team members assisted the respondents who faced difficulties in understanding certain items in the questionnaire.

\subsection{Ethical Approval}

Ethical approval for this study was obtained from the Medical Research Ethical Committee (MREC), Ministry of Health, Malaysia (NMRR-14-1117-19586).

\subsection{Measures}

This study used self-constructed questionnaires which consist of the socio-demographic characteristic; including age, gender, race, level of education, marital status and smoking status. The questionnaire also assessed the awareness of the respondents on e-cigarette, whether they had ever used and the reason why they initiate the e-cigarette. The knowledge of e-cigarettes was assessed by using the questions; "Do you know e-cigarettes?". Those who had answered they knew about e-cigarette but did not use it, had ever used it before but stopped using it and currently use it together with conventional cigarettes, were considered respondents who were aware of e-cigarettes and categorized into two groups which were non-users and users of e-cigarettes. Another knowledge questions that were assessed are "Is e-cigarette more harmful than a conventional cigarette?", "Does e-cigarette contains nicotine?", "Is e-cigarettes are being regulated in Malaysia?" and "Can e-cigarettes used in public places?" The risk factors associated with the initiation of e-cigarettes use was assessed by the question "Why did you use an e-cigarette?" with multiple choice answers (health reason, support from family and friends, e-cigarettes are inexpensive, variety of flavours, curiosity to try, conventional cigarettes are banned in public places, to reduce conventional cigarettes). To assess the reasons for the users to stop using e-cigarettes, the respondents were asked to answer the question; "Why did you stop using an e-cigarette?" with multiple choice of answers (less satisfaction, difficulty to get flavours, causes health problems, worried about the danger of e-cigarettes).

\subsection{Data Analysis}

The data was analyzed using SPSS IBM Corp. 2011 Version 20.0. The descriptive statistic of the continuous variable was described as mean and standard deviation whereby categorical variables describe frequency and percentage. The respondent's knowledge of e-cigarettes 
was presented in the form of categorical data. Bivariate analysis was performed by using the chi-square test to identify the factors of initiating e-cigarettes use among current users and former users. Multivariate analysis using multiple logistic regression was performed to establish the significant predictors of initiating e-cigarettes. The significance level was set at $\mathrm{p}<0.05$.

\section{Results}

Table 1 shows the socio-demographic characteristics of the respondents. A total of 1254 respondents were recruited, with $69.7 \%$ were males. More than half of them were Malays (66.1\%), followed by other ethnicities (Bumiputra Sabah/Sarawak) (22.2\%), Chinese (6.7\%), and Indian (5.0\%). The mean age of respondents was $35.80 \pm 11.49$ years and the highest number of respondents came from the age group of $31-40$ years $(32.1 \%)$. Most of the respondents had educational levels until secondary school $(55.1 \%)$ and were unmarried $(66.2 \%)$. The majority of them $(73.6 \%)$ were aware of e-cigarette's existence, while $13.2 \%$ were e-cigarettes users.

Table 1. Socio-demographic characteristics of the respondents $(N=1254)$.

\begin{tabular}{|c|c|c|c|}
\hline Characteristic & $n$ & $\%$ & Mean \pm SD \\
\hline \multicolumn{4}{|l|}{ Sex } \\
\hline Male & 874 & 69.7 & \\
\hline Female & 380 & 30.3 & \\
\hline \multicolumn{4}{|l|}{ Ethnicity $(n=1250)$} \\
\hline Malay & 826 & 66.1 & \\
\hline Chinese & 84 & 6.7 & \\
\hline Indian & 63 & 5.0 & \\
\hline Age groups $(n=1241)$ & & & $35.80 \pm 11.49$ years \\
\hline$\leq 20$ & 71 & 5.7 & \\
\hline $21-30$ & 392 & 31.6 & \\
\hline $31-40$ & 398 & 32.1 & \\
\hline $41-50$ & 228 & 18.4 & \\
\hline$\geq 51$ & 152 & 12.2 & \\
\hline \multicolumn{4}{|l|}{ Education level $(n=1241)$} \\
\hline Secondary school & 684 & 55.1 & \\
\hline STPM / Diploma & 384 & 30.9 & \\
\hline Degree / Master /PHD & 120 & 9.7 & \\
\hline \multicolumn{4}{|l|}{ Marital status $(n=1250)$} \\
\hline Married & 382 & 30.6 & \\
\hline Single & 828 & 66.2 & \\
\hline Divorce / widower & 40 & 3.2 & \\
\hline \multicolumn{4}{|c|}{ Aware of the existence of e-cigarettes } \\
\hline Yes & 923 & 73.6 & \\
\hline No & 331 & 26.4 & \\
\hline \multicolumn{4}{|l|}{ Usage of e-cigarettes $(n=923)$} \\
\hline Yes & 122 & 13.2 & \\
\hline No & 801 & 86.8 & \\
\hline
\end{tabular}

Based on table 2, most of the respondents were not sure e-cigarette is safer $(52.3 \%)$ and a substantial number agreed it is not safer (34.1\%). Meanwhile, 35.6\% knew that it consisted of nicotine and $45.5 \%$ were not sure e-cigarettes had nicotine. Most of them (42.6\%) were not sure regarding specific regulations on e-cigarette, and $41.6 \%$ said there was no regulation about e-cigarette. $37.2 \%$ said e-cigarettes could not be used in the smoking free zone and $36.0 \%$ were not sure about it.

Table 2. Knowledge related to e-cigarettes of the respondents.

\begin{tabular}{|c|c|c|}
\hline Variables & $\mathbf{n}$ & $\%$ \\
\hline \multicolumn{3}{|c|}{ E-cigarette is safer $(n=928)$} \\
\hline Yes & 127 & 13.6 \\
\hline No & 316 & 34.1 \\
\hline Not Sure & 485 & 52.3 \\
\hline \multicolumn{3}{|c|}{ E-cigarette has nicotine $(n=930)$} \\
\hline Yes & 331 & 35.6 \\
\hline No & 176 & 18.9 \\
\hline \multicolumn{3}{|c|}{ E-cigarette has regulation $(n=930)$} \\
\hline Yes & 147 & 15.8 \\
\hline No & 387 & 41.6 \\
\hline Not Sure & 396 & 42.6 \\
\hline \multicolumn{3}{|c|}{ E-cigarette can use in the smoking free zone $(n=927)$} \\
\hline Yes & 248 & 26.8 \\
\hline
\end{tabular}




\begin{tabular}{lll}
\hline Variables & $\mathbf{n}$ & $\mathbf{\%}$ \\
\hline No & 345 & 37.2 \\
Not sure & 334 & 36.0 \\
\hline
\end{tabular}

As shown in Table 3, the item e-cigarettes are safer was associated with usage status where the higher proportion of former users $(96.6 \%)$ agreed that e-cigarettes are not safe and cause them to stop using it as compared to current users $(79.4 \%)(\mathrm{p}=0.002)$. A significant association was found between curiosity to try and usage status in which former user has a higher curiosity to try $(55.7 \%)$ than the currents users $(\mathrm{p}=0.004)$. A variety of flavours has a significant association between usage status as current users $(58.8 \%)$ used e-cigarettes due to a variety of flavours than the former users $(38.6 \%)(\mathrm{p}=0.044)$. No association was observed between other factors and e-cigarettes usage status.

Table 3. Association between the factors of initiating e-cigarettes use and usage status.

\begin{tabular}{|c|c|c|c|c|c|}
\hline \multirow{2}{*}{ Variables } & \multicolumn{2}{|c|}{ E-cigarette current users $n=34$} & \multicolumn{2}{|c|}{ E-cigarette former users $n=88$} & \multirow[t]{2}{*}{$p$-value } \\
\hline & $\mathbf{n}$ & $\%$ & $\mathbf{n}$ & $\%$ & \\
\hline \multicolumn{6}{|c|}{ E-cigarette is safer } \\
\hline Yes & 7 & 20.6 & 3 & 3.4 & \multirow{2}{*}{$0.002^{*}$} \\
\hline No & 27 & 79.4 & 85 & 96.6 & \\
\hline \multicolumn{6}{|c|}{ Curiosity to try } \\
\hline Yes & 9 & 26.5 & 49 & 55.7 & \multirow{2}{*}{$0.004^{*}$} \\
\hline No & 25 & 73.5 & 39 & 44.3 & \\
\hline \multicolumn{6}{|c|}{ Variety of flavours } \\
\hline Yes & 20 & 58.8 & 34 & 38.6 & \multirow{2}{*}{$0.044^{*}$} \\
\hline No & 14 & 41.2 & 54 & 61.4 & \\
\hline \multicolumn{6}{|c|}{ To save money } \\
\hline Yes & 13 & 38.2 & 21 & 23.9 & \multirow{2}{*}{0.112} \\
\hline No & 21 & 61.8 & 67 & 76.1 & \\
\hline \multicolumn{6}{|c|}{ To smoke in a place where cigarette smoking is banned } \\
\hline Yes & 5 & 14.7 & 10 & 11.4 & \multirow{2}{*}{0.614} \\
\hline No & 29 & 85.3 & 78 & 88.6 & \\
\hline \multicolumn{6}{|c|}{ To reduce tobacco cigarette consumption } \\
\hline Yes & 10 & 29.4 & 24 & 27.3 & \multirow{2}{*}{0.813} \\
\hline No & 24 & 70.6 & 64 & 72.7 & \\
\hline \multicolumn{6}{|c|}{ Substitute for a tobacco cigarette } \\
\hline Yes & 9 & 26.5 & 25 & 28.4 & \multirow{2}{*}{0.830} \\
\hline No & 25 & 73.5 & 63 & 71.6 & \\
\hline \multicolumn{6}{|c|}{ Smoking status } \\
\hline Smoker & 27 & 79.4 & 75 & 85.2 & \multirow{2}{*}{0.437} \\
\hline Non-smoker & 7 & 20.6 & 13 & 14.8 & \\
\hline
\end{tabular}

${ }^{*} p<0.05$

Multiple logistic regression (Table 4) was performed to determine the significant predictors of initiating e-cigarettes. The findings showed that curiosity to try and e-cigarettes are safer are the predictors of initiating e-cigarettes. The respondents who believe that e-cigarettes are safer than tobacco cigarettes have 6.12 times chance to initiate using e-cigarette when considering other factors $(O R=6.12$, $p=0.018$ ). Meanwhile, those who used e-cigarettes because of the curiosity to try had 0.32 times the chance to initiate e-cigarettes use $(O R=0.32, p=0.018)$. The other variables were not related to e-cigarettes initiation.

Table 4. Multiple logistic regression of the factors of initiating e-cigarettes use.

\begin{tabular}{lllll}
\hline Variables & ${\text { Crude } \mathbf{O R}^{\mathbf{a}} \mathbf{( 9 5 \% C I )}}$ & Adjusted OR $^{\mathbf{b}} \mathbf{( 9 5 \% C I )}$ & Wald Statistics $^{\mathbf{b}}(\mathbf{d f})$ & $\mathbf{p}^{- \text {value }} \mathbf{b}^{\mathbf{b}}$ \\
\hline Curiosity to try & $0.29(0.12,0.68)$ & $0.32(0.13,0.82)$ & $5.62(1)$ & $0.018^{*}$ \\
E-cigarette is safer & $7.35(1.78,30.39)$ & $6.12(1.37,27.39)$ & $5.62(1)$ & $0.018^{*}$ \\
Variety of flavour & $2.27(1.01,5.08)$ & $2.46(0.99,6.10)$ & $3.77(1)$ & 0.052 \\
To save money & $1.98(0.85,4.61)$ & $1.85(0.73,4.72)$ & $1.67(1)$ & 0.196 \\
To smoke in a place where cigarette smoking is banned & $1.35(0.42,4.27)$ & $0.84(0.22,3.20)$ & $0.07(1)$ & 0.795 \\
\hline
\end{tabular}

${ }^{*} p<0.05$

${ }^{\mathrm{a}}$ Simple logistic regression, ${ }^{\mathrm{b}}$ Multiple logistic regression

The model reasonably fits well. Model assumptions are met. There are not interactions and multicollinearity problems.

\section{Discussion}

A high percentage of awareness of the existence of e-cigarette $(73.6 \%)$ and a low prevalence of e-cigarettes users
(13.2\%) were observed in this study. The findings appeared to be higher than the findings from the Global Adult Tobacco Survey Malaysia 2011 which reported about $21.0 \%$ of adults in Malaysia had heard about E-cigarettes, and $0.8 \%$ use these 
devices [13]. Meanwhile, the results from the 2014 Tobacco Products and Risk Perceptions Survey among 5717 USA adults revealed that $91.9 \%$ of USA adults had heard about e-cigarettes and an estimated $14.9 \%$ of USA adults have ever used and $4.9 \%$ were current users of e-cigarettes [14]. The rise in awareness of the existence of e-cigarette among the public could not reflect their knowledge of e-cigarettes. The majority of the respondents knew the existence of e-cigarettes, but the in-depth understanding of e-cigarettes was still unsatisfactory. This study found that most of the respondents are not sure e-cigarettes were safer, contain nicotine and have specific regulations of e-cigarettes. Similarly, a survey in the United States reported that half of the young adults' had a lack of knowledge on the harmful of e-cigarettes [15]. Contradict findings in Spain found that nearly half of the adults believed that e-cigarettes were less harmful than conventional cigarettes [6]. Meanwhile, another study reported the adolescents believed that e-cigarettes did not have nicotine or did not know whether they had nicotine [16]. Several studies observed that a higher level of tobacco-related knowledge was associated with a positive attitude towards smoking cessation $[17,18]$. This suggests that appropriate information on e-cigarettes should be adequately disseminated to the general population to promote healthy behaviours and positive attitudes toward smoking.

This study reported that curiosity to try and e-cigarettes are safer are the predictors of initiating e-cigarettes. A significantly higher percentage of the former e-cigarette's users agreed that it is unsafe and causes them to stop using it. This result suggested that the former user believed that e-cigarettes were safer prior to their cessation. Likewise, other studies agreed that e-cigarettes are less harmful than regular cigarettes [16, 19, 20]. Such finding was believed to be influenced by a common misconception that e-cigarettes are safer than conventional cigarettes [21]. According to the US Department of Health and Human Services (2016), the emerging evidence reveals that most e-cigarettes contain nicotine, potentially causing adverse health effects and harmful to pregnant women, toxic to developing fetus and disrupting the child brain development [22].

Another significant factor of initiating e-cigarettes was a higher curiosity to try among the former user. Several studies also reported similar findings in which the most common reason for initiating e-cigarettes is curious to try among adolescents $[23,24]$ and young adults $[25,26]$ (Biener et al., 2015; Sutfin et al., 2015). Similarly, results from a qualitative study also found that e-cigarette initiation was facilitated by motivation, including curiosity to try [27]. Perhaps they are motivated to try when they heard and see their friend used it. Social influences such as family and friends who are e-cigarettes users may encourage someone's decision-making to initiate e-cigarettes.

Meanwhile, the factor of e-cigarettes has a variety of flavours significantly higher among the current users for initiating e-cigarettes use. This result agrees with other studies conducted in the USA among adolescents, youths and adults $[16,28,29]$. This particular result can be explained by the manner of e-cigarettes are being advertised and promoted that may influence initiation especially among youth and young adults. For example, e-cigarettes are marketed via the Internet, print, retail, and TV/movies by promoting various flavours such as fruits, sweets, and drinks (coffee, alcoholic beverages) to attract users' attention [4, 30]. Nonetheless, one should be concerned about e-cigarettes with various flavours containing nicotine that can give an addictive effect on the users and may lead to conventional cigarette use in the future.

Besides, this study also found the main reason smokers quit using e-cigarettes was that it did not give satisfaction compared to conventional cigarettes, while for non-smoker was due to worry about the danger of e-cigarettes. Some people agreed that e-cigarettes are less addictive and less satisfactory than conventional cigarettes, especially when it contains less nicotine [19, 31]. In addition, a study reported that those who attempted to quit smoking by using e-cigarettes were relapsed back to smoking due to less satisfactory [6].

This study has several limitations. First, this is a cross-sectional study that cannot determine the temporal or causal inferences. Emerging research has found that e-cigarettes can cause adverse health effects and harmful to our bodies [22]. Thus, longitudinal studies are warranted to explore the health effects of long-term e-cigarettes use. Second, this study only recruited respondents who were visiting public hospitals and clinics that cannot be generalized to other populations in different settings. In addition, this study only focused on adults in Malaysia, which did not include adolescents as recent studies suggested a higher prevalence of e-cigarette use among them [32-34]. Hence, future studies are needed to investigate the use of e-cigarette in this population. Despite these limitations, this study provided information related to knowledge, factors of e-cigarettes initiation and reasons for quitting e-cigarettes among adults in Malaysia, which has not been previously studied.

\section{Conclusions}

In conclusion, this study suggested that Malaysian had a high awareness of the existence of e-cigarette, but low in knowledge related to e-cigarettes. This study also highlighted the significant predicting factor of initiating e-cigarettes were a curiosity to try and e-cigarettes are safer. This study observed that the main reason smokers quit using e-cigarettes was that it did not give satisfaction compared to conventional cigarettes, while for non-smoker was due to worry about the danger of e-cigarettes. Given the negative health effect of e-cigarettes use, more research is needed to determine the knowledge of health risk effects among users and non-users. Therefore, future health communication intervention is crucial to provide correct information about e-cigarettes and give awareness to all age groups in reducing intention to experiment with e-cigarettes. It is important to obtain information about the general population's perception of the harmful health effects of e-cigarettes in order to develop regulations rationally and effectively in the future. 


\section{Author Contributions}

ABR led the study, supervised all aspects of its conduction and wrote the manuscript. MYA assisted with data analysis and interpretation of data and wrote the manuscript. MIS, MKK, SFM, NA, ZMZ, NJ and ABR assisted with the study design, questionnaire item and development. All authors helped to conceptualize ideas, interpret findings and review drafts of the manuscript. All authors read and approved the final manuscript.

\section{Funding}

This study was funded by Ministry of Health Malaysia research grant.

\section{Conflicts of Interest}

Authors have completed and submitted the ICMJE Form for Disclosure of Potential Conflicts of Interest and none was reported.

\section{Acknowledgements}

We would like to thank the Director-General of Health Malaysia for his permission to publish this paper. We would also like to thank those who were involved in the study and who assisted in the collection and management of the data for their support and co-operation.

\section{References}

[1] Etter, J. F. (2010). Electronic cigarettes: A survey of users. BMC Public Health, 10 (231), 1-7. https://doi.org/10.1186/1471-2458-10-231

[2] Brandon, T. H., Goniewicz, M. L., Hanna, N. H., Hatsukami, D. K., Herbst, R. S., Hobin, J. A., Ostroff, J. S., Shields, P. G., Toll, B. A., Tyne, C. A., Viswanath, K., \& Warren, G. W. (2015). Electronic nicotine delivery systems: A policy statement from the American Association for Cancer Research and the American Society of Clinical Oncology. Clinical Cancer Research, 21 (3), 514-525. https://doi.org/10.1158/1078-0432.CCR-14-2544

[3] Ayers, J. W., Ribisl, K. M., \& Brownstein, J. S. (2011). Tracking the rise in popularity of electronic nicotine delivery systems (electronic cigarettes) using search query surveillance. American Journal of Preventive Medicine, 40 (4), 448-453. https://doi.org/10.1016/j.amepre.2010.12.007

[4] Bullen, C., López-Núñez, C., \& Knight-West, O. (2016). E-cigarettes in smoking cessation: $\mathrm{A}$ harm reduction perspective. Clinical Pharmacist, 8 (4), 1-11. https://doi.org/10.1211/CP.2016.20200851

[5] Notley, C., Ward, E., Dawkins, L., \& Holland, R. (2018). The unique contribution of e-cigarettes for tobacco harm reduction in supporting smoking relapse prevention. Harm Reduction Journal, $15 \quad$ (1), 1-12. https://doi.org/10.1186/s12954-018-0237-7
[6] Martínez-Sánchez, J. M., Fu, M., Martín-Sánchez, J. C., Ballbè, M., Saltó, E., \& Fernández, E. (2015). Perception of electronic cigarettes in the general population: does their usefulness outweigh their risks? BMJ Open, 5(11), e009218. https://doi.org/10.1136/bmjopen-2015-009218

[7] Pepper, J. K., Emery, S. L., Ribisl, K. M., Rini, C. M., \& Brewer, N. T. (2015). How risky is it to use e-cigarettes? Smokers' beliefs about their health risks from using novel and traditional tobacco products Jessica. Journal of Behaviour Medicine, $\quad 38 \quad$ (2), 318-326. https://doi.org/10.1007/s10865-014-9605-2.

[8] Tan, A. S. L., \& Bigman, C. A. (2014). E-cigarette awareness and perceived harmfulness: Prevalence and associations with smoking-cessation outcomes. American Journal of Preventive $\begin{array}{llll}\text { Medicine, } & 47 & \text { (2), }\end{array}$ https://doi.org/10.1016/j.amepre.2014.02.011

[9] Center for Tobacco Control Research and Education. (2014). 129 public health and medical authorities from 31 countries write WHO DG Chan urging evidence-based approach to ecigs. https://tobacco.ucsf.edu/sites/g/files/tkssra4661/f/u9/Chan-lett er-June16 PST FINAL with 129 sigs.pdf

[10] Centers for Disease Control and Prevention. (2020). Dual use of tobacco products. https://www.cdc.gov/tobacco/campaign/tips/diseases/dual-tob acco-use.html

[11] Bernat, D., Gasquet, N., Wilson, K. O. D., Porter, L., \& Choi, K (2018). Electronic cigarette harm and benefit perceptions and use among youth. American Journal of Preventive Medicine, 55 (3), 361-367. https://doi.org/10.1016/j.amepre.2018.04.043

[12] Trumbo, C. W., \& Harper, R. (2013). Use and perception of electronic cigarettes among college students. Journal of American College Health, 61 (3), 149-155. https://doi.org/10.1080/07448481.2013.776052.Us13.

[13] Institute of Public Health. (2012). Global Adult Tobacco Survey (GATS) Malaysia 2011. National Institute of Health, Ministry of Health.

[14] Weaver, S. R., Majeed, B. A., Pechacek, T. F., Nyman, A. L., Gregory, K. R., \& Eriksen, M. P. (2016). Use of electronic nicotine delivery systems and other tobacco products among USA adults, 2014: Results from a national survey. International Journal of Public Health, 61 (2), 177-188. https://doi.org/10.1007/s00038-015-0761

[15] Sutfin, E. L., McCoy, T. P., Morrell, H. E. R., Hoeppner, B. B., \& Wolfson, M. (2013). Electronic cigarette use by college students. Drug and Alcohol Dependence, 131 (3), 214-221. https://doi.org/10.1016/j.drugalcdep.2013.05.001

[16] Pepper, J K, Ribisl, K. M., \& Brewer, N. T. (2016). Adolescents' interest in trying flavoured e-cigarettes. Tobacco Control, 25, ii62-ii66. https://doi.org/10.1136/tobaccocontrol-2016-053174

[17] Dawood, O. T., Rashan, M. A., Hassali, M. A., \& Saleem, F. (2016). Knowledge and perception about health risks of cigarette smoking among Iraqi smokers. Journal of Pharmacy and Bioallied Sciences, 8 (2), 146-151. https://doi.org/10.4103/0975-7406.171738

[18] Park, J., Lim, M. K., Hwa Yun, E., Oh, J. K., Jeong, B. Y., Cheon, Y., \& Lim, S. (2018). Influences of tobacco-related knowledge on awareness and behavior towards smoking. Journal of Korean Medical Science, 33 (47), 1-10. https://doi.org/10.3346/jkms.2018.33.e302 
[19] Choi, K., \& Forster, J. (2013). Characteristics associated with awareness, perceptions, and use of electronic nicotine delivery systems among young US Midwestern adults. Research and $\begin{array}{llll}\text { Practice, } & 103 & \text { (3), } & \text { 556-561. }\end{array}$ https://doi.org/10.2105/AJPH.2012.300947

[20] Wackowski, O. A., Bover Manderski, M. T., \& Delnevo, C. D. (2015). Smokers' sources of e-cigarette awareness and risk information. Preventive Medicine Reports, 2, 906-910. https://doi.org/10.1016/j.pmedr.2015.10.006

[21] Kanyadan, V., \& Ganti, L. (2019). E-cigarette awareness among young adults: A Pilot Survey Study. https://doi.org/10.7759/cureus.5234

[22] U.S. Department of Health and Human Services. (2016). E-cigarette use among youth and young adults: A report of the surgeon general. In JAMA Pediatrics. https://doi.org/10.1001/jamapediatrics.2016.4662

[23] Surís, J.-C., Berchtold, A., \& Akre, C. (2015). Reasons to use e-cigarettes and associations with other substances among adolescents in Switzerland. Drug and Alcohol Dependence, 153 ,

https://doi.org/10.1016/j.drugalcdep.2015.05.034

$140-144$.

[24] Lee, J., Lee, S., \& Cho, H.-J. (2017). The relation between frequency of e-cigarette use and frequency and intensity of cigarette smoking among South Korean adolescents. International Journal of Environmental Research and Public Health, 14 (3), 305. https://doi.org/10.3390/ijerph14030305

[25] Biener, L., Song, E., Sutfin, E. L., Spangler, J., \& Wolfson, M. (2015). Electronic cigarette trial and use among young adults: Reasons for trial and cessation of vaping. International Journal of Environmental Research and Public Health, 12 (12), 16019 16026. https://doi.org/10.3390/ijerph121215039

[26] Sutfin, E. L., Reboussin, B. A., Debinski, B., Wagoner, K. G., Spangler, J., \& Wolfson, M. (2015). The impact of trying electronic cigarettes on cigarette smoking by college students: A prospective analysis. American Journal of Public Health, 105 (8), e83-e89. https://doi.org/10.2105/AJPH.2015.302707

[27] Wadsworth, E., Neale, J., McNeill, A., \& Hitchman, S. C. (2016). How and why do smokers start using e-cigarettes?
Qualitative study of vapers in London, UK. International Journal of Environmental Research and Public Health, 13 (7). https://doi.org/10.3390/ijerph13070661

[28] Chen, J. C., Das, B., Mead, E. L., \& Borzekowski, D. L. G. (2019). Flavored e-cigarette use and cigarette smoking susceptibility among youth. 3 (1), 68-80. https://doi.org/10.18001/TRS.3.1.7.Flavored

[29] Russell, C., McKeganey, N., Dickson, T., \& Nides, M. (2018). Changing patterns of first e-cigarette flavor used and current flavors used by 20,836 adult frequent e-cigarette users in the USA. Harm Reduction Journal, 15 (1), 1-14. https://doi.org/10.1186/s12954-018-0238-6

[30] Mantey, D. S., Cooper, M. R., Clendennen, S. L., Pasch, K. E., \& Perry, C. L. (2016). E-cigarette marketing exposure is associated with e-cigarette use among US youth. Journal of Adolescent Health, 58 (6), 686-690. https://doi.org/10.1016/j.jadohealth.2016.03.003

[31] Etter, J. F. (2015). Explaining the effects of electronic cigarettes on craving for tobacco in recent quitters. Drug and Alcohol Dependence, $148, \quad 102-108$. https://doi.org/10.1016/j.drugalcdep.2014.12.03

[32] Hrywna, M., Bover Manderski, M. T., \& Delnevo, C. D. (2020) Prevalence of electronic cigarette use among adolescents in New Jersey and association with social factors. JAMA Network Open, 3 (2), e1920961. https://doi.org/10.1001/jamanetworkopen.2019.20961

[33] Soteriades, S., Barbouni, A., Rachiotis, G., Grevenitou, P., Mouchtouri, V., Pinaka, O., Dadouli, K., \& Hadjichristodoulou, C. (2020). Prevalence of electronic cigarette use and its determinants among 13-to-15-year-old students in greece: results from the 2013 global youth tobacco survey (GYTS). International Journal of Environmental Research and Public Health, 17 (5). https://doi.org/10.3390/ijerph17051671

[34] Walker, N., Parag, V., Wong, S. F., Youdan, B., Broughton, B., Bullen, C., \& Beaglehole, R. (2020). Use of e-cigarettes and smoked tobacco in youth aged $14-15$ years in New Zealand: findings from repeated cross-sectional studies (2014-19). The Lancet Public Health, 5 (4), e204-e212. https://doi.org/10.1016/S2468-2667(19)30241-5 